\title{
Audiology Neurotology
}

\section{The Science of Hearing and Balance}

Journal founded 1996 by Manfried Hoke (Editor-in-Chief 1996-2004)

Editor-in-Chief

Jeffrey P. Harris - UCSD School of Medicine, San Diego, CA, USA

\section{Assistant Editor-in-Chief}

Elina Kari - University of California, San Diego, CA, USA

\section{Section Editors}

Paul Avan - Laboratory of Sensory Biophysics, Clermont-Ferrand, France Audiology

John P. Carey - Johns Hopkins Medicine, Baltimore, MD, USA

Vestibular Section

Joseph Nadol - Massachusetts Eye \& Ear Infirmary, Boston, MA, USA

Clinical Otology/Neurotology

Allen F. Ryan - University of California San Diego, La Jolla, CA, USA

Molecular Otology, Molecular Genetics, Hair Cell and Neural Regeneration

Christoph E. Schreiner - University of California San Francisco, San Francisco, CA, USA

Central Auditory Processing

Su-Hua Sha - Medical University of South Carolina, Charleston, SC, USA

Inner Ear Biochemistry, Pharmacology, Ototoxicity and Protection

\section{Associate Editors}

Ksenia Aaron - Stanford University, Palo Alto, CA, USA

Daniela Carvalho - UCSD Pediatric Otolaryngology, San Diego, CA, USA

Wade W. Chien - National Institutes of Health, Bethesda, MD, USA

Maura K. Cosetti - New York Eye and Ear Infirmary of Mount Sinai, New York, NY, USA

Justin S. Golub - Columbia University, New York, NY, USA

Joan G. Hewitt - Project TALK, Inc., Encinitas, CA, USA

Daniel Jethanamest - NYU School of Medicine, New York, NY, USA

Matthew Kircher - Loyola University Medical Center, Maywood, IL, USA

Ruwan Kiringoda - Sutter Health, Fremont, CA, USA

\section{Official Organ of}

Deutsche Gesellschaft für Audiologie e.V.
Robert F. Labadie - Vanderbilt University Medical Center, Nashville, TN, USA

Teddy McRackan - Medical University of South Carolina, Charleston, SC, USA

Aaron C. Moberly - The Ohio State University, Columbus, OH, USA

Julie K. Purdy - Rady Children's Hospital, San Diego, CA, USA

Alejandro Rivas - Vanderbilt University, Nashville, TN, USA

(Continued on next page) 


\section{Audiology Neurotology}

(Continued)

Isabelle Schrauwen - Columbia University Medical Center, New York, NY, USA

Kareem Tawfik - University of California, San Diego, CA, USA

Joe Ursick - Otologic Center, Kansas City, MT, USA

Esther Vivas - Emory University, Atlanta, GA, USA

\section{Editorial Board Members}

Maurizio Barbara - University La Sapienza, Rome, Italy

Olivier Bertrand - Centre Hospitalier Le Vinatier, Bron, France

Thomas Brandt - Ludwig Maximilians University, Munich, Germany

Barbara Canlon - Karolinska Institute, Stockholm, Sweden

Douglas A. Cotanche - Harvard NIHL Research Group, Boston, MA, USA

C.W.R.J. Cremers - University Medical Center St. Radboud, Nijmegen, The Netherlands

Norbert Dillier - University Hospital, Zurich, Switzerland

Manuel Don - Electrophysiology Laboratory, Los Angeles, CA, USA

Jill B. Firszt - Washington University, St. Louis, MO, USA

Andrew Forge - UCL Ear Institute, London, UK

Bernard Fraysse - C.H.U. Purpan, Toulouse, France

Rick Friedman - University of California, San Diego, CA, USA

Bruce J. Gantz - University of lowa, lowa City, IA, USA

Anthony W. Gummer - University of Tübingen, Tübingen, Germany

James W. Hall, III. - University of Florida, Gainesville, FL, USA

Joseph W. Hall - University of North Carolina, Chapel Hill, NC, USA

Michael Halmagyi - Royal Prince Alfred Hospital, Camperdown, NSW, Australia

Rudolf Häusler - Tiefenauspital, Bern, Switzerland

Vicente Honrubia - David Geffen School of Medicine at UCLA, Los Angeles, CA, USA

Gary D. Housley - University of New South Wales, Sydney, NSW, Australia

Karl-Bernd Hüttenbrink - HNO-Klinik der Universität zu Köln, Cologne, Germany

Pawel J. Jastreboff - Emory University School of Medicine, Atlanta, GA, USA

Margaret A. Kenna - Children's Hospital Boston, Boston, MA, USA

Philippe Lefebvre - University of Liège, Liège, Belgium

Bernd Lütkenhöner - Universitätsklinikum Münster, Münster, Germany

Linda M. Luxon - University College London UCL, London, UK

Geoffrey A. Manley - Carl von Ossietzky University, Oldenburg, Germany

Alessandro Martini - Universitary Hospital of Padova, Padova, Italy

Jennifer R. Melcher - Harvard Medical School, Boston, MA, USA

Brian C.J. Moore - University of Cambridge, Cambridge, UK

David R. Moore - MRC Institute of Hearing Research, Nottingham, UK

Cynthia C. Morton - Harvard Medical School, Boston, MA, USA

Donata Oertel - University of Wisconsin, Madison, WI, USA

Kaoru Ogawa - Keio University, Tokyo, Japan

Stephen J. O'Leary - University of Melbourne, Parkville, VIC, Australia

Alan R. Palmer - MRC Institute of Hearing, Nottingham, UK

Lorne S. Parnes - University of Western Ontario, London, ON, Canada

Jean Luc Puel - University of Montpellier, Montpellier, France

Ramesh Rajan - Monash University, Clayton, VIC, Australia

Yehoash Raphael - University of Michigan, Ann Arbor, MI, USA

J. Thomas Roland, Jr. - NYU Langone Medical Center and NYU School of Medicine,

New York, NY, USA 


\section{Audiology Neurotology}

(Continued)

John J. Rosowski - Massachusetts Eye \& Ear Infirmary, Boston, MA, USA

Rudolf Rübsamen - University of Leipzig, Leipzig, Germany

Mario A. Ruggero - Northwestern University, Evanston, IL, USA

Leonard P. Rybak - SIU School of Medicine, Springfield, IL, USA

Richard Salvi - University of Buffalo, Buffalo, NY, USA

Robert Shannon - House Ear Institute, Los Angeles, CA, USA

Guido F. Smoorenburg - "La Palladienne", Besse sur Issole, France

Haim Sohmer - Hebrew University, Jerusalem, Israel

Olivier Sterkers - Hôpital de la Pitié Salpêtrière, Paris, France

Istvan Sziklai - University of Debrecen, Debrecen, Hungary

Peter R. Thorne - University of Auckland, Auckland, New Zealand

Shin-ichi Usami - Shinshu University, Matsumoto, Japan

P. Ashley Wackym - Rutgers RWJMS, New Brunswick, NJ, USA

Tatsuya Yamasoba - University of Tokyo, Tokyo, Japan

Fan-Gang Zeng - University of California Irvine, Irvine, CA, USA 
S. Karger

Medical and Scientific Publishers

Basel $\cdot$ Freiburg $\cdot$ Hartford $•$ Oxford $•$ Bangkok $\cdot$ Dubai $\cdot$ Kuala Lumpur $•$

Melbourne $\cdot$ Mexico City $\cdot$ Moscow $•$

New Delhi $\bullet$ Paris $\bullet$ Shanghai $\cdot$ Tokyo
Disclaimer

The statements, opinions and data contained in this publication are solely those of the individual authors and contributors and not of the publisher and the editor(s). The appearance of advertisements in the journal is not a warranty, endorsement, or approval of the products or services advertised or of their effectiveness, quality or safety. The publisher and the editor(s) disclaim responsibility for any injury to persons or property resulting from any ideas, methods, instructions or product referred to in the content or advertisements.

Drug Dosage

The authors and the publisher have exerted every effort to ensure that drug selection and dosage set forth in this text are in accord with current recommendations and practice at the time of publication. However, in view of ongoing research, changes in government regulations, and the constant flow of information relating to drug therapy and drug reactions, the reader is urged to check the package insert for each drug for any change in indications and dosage and for added warnings and precautions. This is particularly important when the recommended agent is a new and/or infrequently employed drug.
All rights reserved.

No part of this publication may be translated into other languages, reproduced or utilized in any form or by any means, electronic or mechanical, including photocopying, recording, microcopying, or by any information storage and retrieval system, without permission in writing from the publisher or in the case of photocopying, direct payment of a specified fee to the Copyright Clearance Center (see "General Information").

(c) Copyright $2019 / 2020$ by S. Karger AG,

CH-4009 Basel (Switzerland)

Printed on acid-free and non-aging paper (ISO 9706)

\section{KARGER}




\section{Audiology Neurotology}

No. 1

Review

8 Genetic Polymorphisms and Susceptibility to Sudden Sensorineural Hearing Loss: A Systematic Review Cao, Z.; Gao, J.; Huang, S.; Xiang, H.; Zhang, C.; Zheng, B.; Zhan, X.; Chen, R.; Chen, B. (Wenzhou)

Original Papers

1 Stapes Prosthesis Length: One Size Fits All? Sudhoff, H.; Gehl, H.B.; Boga, E.; Müller, S. (Bielefeld); Wilms, K.; Mutze, S. (Berlin); Todt, I. (Bielefeld)

20 Inappropriate Use of the "Rosowski Criteria" and "Modified Rosowski Criteria" for Assessing the Normal Function of Human Temporal Bones

Morse, R.P. (Coventry); Mitchell-Innes, A. (Birmingham); Prokopiou, A.N. (Coventry); Irving, R.M.; Begg, P.A. (Birmingham)

25 Identification and Clinical Implications of a Novel MYO15A Variant in a Consanguineous Iranian Family by Targeted Exome Sequencing

Zarepour, N.; Koohiyan, M.; Taghipour-Sheshdeh, A.; Nemati-Zargaran, F. (Shahrekord); Saki, N.; Mohammadi-Asl, J. (Ahvaz); Tabatabaiefar, M.A. (Isfahan); Hashemzadeh-Chaleshtori, M. (Shahrekord)

32 Speech Recognition of Cochlear Implant Users Inside a Noisy Helicopter Environment

Caldeira, J.M.A.; Goffi-Gomez, M.V.S.; Imamura, R.; Bento, R.F. (São Paulo)

38 Comparison of Place-versus-Pitch Mismatch between a Perimodiolar and Lateral Wall Cochlear Implant Electrode Array in Patients with Single-Sided Deafness and a Cochlear Implant

Peters, J.P.M.; Bennink, E.; van Zanten, G.A. (Utrecht)

Erratum

No. 2

Review

51 Tophaceous Gout of the Middle Ear: Case Reports and Review of the Literature

Saliba, J. (San Diego, CA); Sakano, H. (San Diego, CA/Rochester, NY); Friedman, R.A.; Harris, J.P. (San Diego, CA)

Original Papers

56 MRI Metal Artifact Reduction Sequence for Auditory Implants: First Results with a Transcutaneous Bone Conduction Implant

Wimmer, W.; Hakim, A.; Kiefer, C.; Pastore-Wapp, M.; Anschuetz, L.; Caversaccio, M.D.; Wagner, F. (Bern)
65 Insulin Receptor and Glucose Transporters in the Mammalian Cochlea

Huerzeler, N.; Petkovic, V.; Sekulic-Jablanovic, M.; Kucharava, K.;

Wright, M.B.; Bodmer, D. (Basel)

77 Cochlear Implant in the Elderly: Results in Terms of Speech Perception and Quality of Life

Forli, F.; Lazzerini, F.; Fortunato, S.; Bruschini, L.; Berrettini, S. (Pisa)

84 Risk Factors and Prognostic Factors of Hearing Impairment in Neonatal Intensive Care Unit-Treated Infants

Umehara, T.; Hosokawa, S.; Kita, J.; Takahashi, G.; Okamura, J.; Nakanishi, H.; Hosokawa, K.; Kyou, K. (Hamamatsu); Hayashi, Y.

(Yokohama); Mineta, H. (Hamamatsu)

90 The Bonebridge in Adults with Mixed and Conductive Hearing Loss: Audiological and Quality of Life Outcomes

Skarżyński, P.H. (Warsaw/Kajetany); Ratuszniak, A.; Król, B.; Kozieł, M.; Osińska, K.; Cywka, K.B.; Sztabnicka, A.; Skarżyński, H. (Kajetany)

100 Clinical Implications of Poloxamer 407 as Packing Material in an Animal Model

Choi, J.E.; Lee, J.-H.; Chang, S.-Y.; Lee, M.Y.; Jung, J.Y. (Cheonan)

No. 3

Review

109 Fluctuating Sensorineural Hearing Loss

Liu, H.; Zhou, K.; Zhang, X. (Shijiazhuang City); Peng, K.A.

(Los Angeles, CA)

Original Papers

117 Audiological Evaluation of Vestibular Schwannoma Patients with Normal Hearing

Salem, N.; Galal, A. (Piacenza/Rome/Alexandria); Mastronardi, V. (Piacenza/ Rome); Talaat, M.; Sobhy, O. (Alexandria); Sanna, M. (Piacenza/Rome)

127 How Does Nonverbal Reasoning Affect Sentence Recognition in Adults with Cochlear Implants and Normal-Hearing Peers? Moberly, A.C.; Mattingly, J.K.; Castellanos, I. (Columbus, OH)

139 Auditory Skills following Cochlear Implantation in Children with the Charge Syndrome

Aragón-Ramos, P.; Pedrero-Escalas, M.-F.; Gavilán, J.; Pérez-Mora, R.; Herrán-Martin, B.; Lassaletta, L. (Madrid)

147 Cochlear Nerve Hypoplasia: Audiological Characteristics in Children and Adults

Cinar, B.C.; Tahir, E.; Batuk, M.O.; Yarali, M.; Sennaroglu, G.; Sennaroglu, L. (Ankara)

154 Impairment of Vestibular Function and Balance Control in Patients with Type 2 Diabetes

Li, J. (Beijing); Jiang, J. (Birmingham); Zhang, Y.; Liu, B.; Zhang, L. (Beijing)

\section{KARGER}

E-Mail karger@karger.com www.karger.com
(C) 2020 S. Karger AG, Basel

Access to full text and tables of contents, including tentative ones for forthcoming issues: www.karger.com/aud_issues 
No. 4

Systematic Review

161 Genetics of Hereditary Hearing Loss in the Middle East: A Systematic Review of the Carrier Frequency of the GJB2 Mutation (35delG)

Koohiyan, M. (Shahrekord)

Original Papers

166 Audiovestibular Phenotypes and Advanced Magnetic Resonance Imaging Features of Cochlin Gene Mutation Carriers

Conte, G.; Lo Russo, F.; Caschera, L.; Zanetti, D.; Castorina, P.; Sina, C. Triulzi, F.; Di Berardino, F. (Milan)

174 Critical Factors for Binaural Hearing in Children with Bilateral Sequential Cochlear Implantation: First Implant Performance and Inter-Implant Interval

Jang, J.H.; Roh, J.-M.; Choo, O.S.; Kim, Y.-J.; Kim, H.; Park, H.Y.; Choung, Y.-H. (Suwon)

183 Eradicating Otomycosis with Terbinafine Solution: Basic and Clinical Investigation Yang, T.-H.; Young, Y.-H. (Taipei)

191 A Smartphone-Based Weber Test May Discriminate between a Conductive and a Sensorineural Hearing Loss Ungar, O.J.; Handzel, O.; Cavel, O.; Oron, Y. (Tel Aviv)

197 Outcomes after Application of Active Bone Conducting Implants

Koro, E.; Werner, M. (Umeå)

206 Data Logging Evidence of Cochlear Implant Use in Single-Sided and Bilateral Deafness

Rauch, A.-K.; Kagermann, S.; Wesarg, T.; Jakob, T.F.; Aschendorff, A. Ihorst, G.; Speck, I.; Arndt, S. (Freiburg)

\section{No. 5}

Original Papers

217 Rat Model of Ménière's Attack: Intratympanic Injection of Potassium Chloride Produces Direction-Changing Spontaneous Nystagmus and Hearing Fluctuations Kamakura, T. (Suita/Osaka); Kitahara, T. (Kashihara); Kondo, M. (Suita); Horii, A. (Niigata); Hanada, Y.; Takimoto, Y. (Suita); Ishida, Y. (Suita/ Sendai); Nakamura, Y.; Imai, T.; Inohara, H.; Shimada, S. (Suita)

224 High Risk of Sudden Sensorineural Hearing Loss in Several Autoimmune Diseases according to a Population-Based National Sample Cohort Study

Jeong, J.; Lim, H.; Lee, K.; Hong, C.E.; Choi, H.S. (Goyang)

231 Wide-Band Tympanometry Results during an Acute Episode of Ménière's Disease

Cakir Cetin, A.; Gurkan, S.; Kirkim, G.; Guneri, E.A. (Izmir)

237 Sustained-Release Triamcinolone Acetonide Hydrogels Reduce Hearing Threshold Shifts in a Model for Cochlear Implantation with Hearing Preservation

Honeder, C.; Zhu, C.; Gausterer, J.C.; Schöpper, H.; Ahmadi, N.; Saidov, N.; Nieratschker, M.; Gabor, F.; Arnoldner, C. (Vienna)

245 Influence of Cochlear Implantation on Postural Control and Risk of Falls

Louza, J.; Rösel, C.; Gürkov, R.; Krause, E.; Ihler, F. (Munich)

253 Are There Cochlear Dead Regions Involved in Hearing Loss after Cisplatin Ototoxicity?

Schultz, C.; Pecora Liberman, P.H.; Schmidt Goffi-Gomez, M.V. (São Paulo)
258 A Novel Pathogenic Variant in the CABP2 Gene Causes Severe Nonsyndromic Hearing Loss in a Consanguineous Iranian Family

Koohiyan, M. (Isfahan/Shahrekord); Noori-Daloii, M.R. (Tehran); Hashemzadeh-Chaleshtori, M. (Shahrekord); Salehi, M.; Abtahi, H.; Tabatabaiefar, M.A. (Isfahan)

264 Cochlear Place of Stimulation Is One Determinant of Cochlear Implant Sound Quality

Dorman, M.F.; Cook Natale, S. (Tempe, AZ); Baxter, L. (Phoenix, AZ); Zeitler, D.M. (Seattle, WA); Carlson, M.L. (Rochester, MN); Noble, J.H. (Nashville, TN)

270 Erratum

No. 6

Original Papers

271 Cochlear Dead Regions in Sporadic Unilateral Vestibular Schwannomas Using the Threshold-Equalizing Noise Test Byun, H.; Cho, Y.-S. (Seoul); Hong, S.H. (Changwon); Moon, I.J. (Seoul)

279 Is Early Cochlear Implant Device Activation Safe for All on-the-Ear and off-the-Ear Sound Processors? Batuk, M.O.; Yarali, M.; Cinar, B.C.; Kocabay, A.P.; Bajin, M.D. Sennaroglu, G.; Sennaroglu, L. (Ankara)

285 Effects of Glycerol Test on Resonance Frequency in Patients with Ménière's Disease Oz, I.; Hizal, E.; Cam, O.H.; Ozluoglu, L.N. (Ankara)

293 Treatment Outcome of Auditory and Frontal Dual-Site rTMS in Tinnitus Patients and Changes in Magnetoencephalographic Functional Connectivity after rTMS: Double-Blind Randomized Controlled Trial Noh, T.-S.; Kyong, J.-S.; Park, M.K.; Lee, J.H.; Oh, S.H.; Chung, C.K.; Kim, J.S.; Suh, M.-W. (Seoul)

299 Cochlear Implantation with the CI512 and CI532 Precurved Electrode Arrays: One-Year Speech Recognition and Intraoperative Thresholds of Electrically Evoked Compound Action Potentials

Videhult Pierre, P.; Eklöf, M.; Smeds, H.; Asp, F. (Stockholm)

309 Amplitude Modulated Noise for Tinnitus Suppression in Tonal and Noise-Like Tinnitus

Schoisswohl, S.; Arnds, J.; Schecklmann, M.; Langguth, B.; Schlee, W. (Regensburg); Neff, P. (Regensburg/Zurich)

322 Acknowledgement to Reviewers 